\title{
Investigating the Degradation Behaviors of a Therapeutic Monoclonal Antibody Associated with pH and Buffer Species
}

\author{
Songyan Zheng, ${ }^{1,2}$ Difei Qiu, ${ }^{1}$ Monica Adams, ${ }^{1}$ Jinjiang Li, ${ }^{1}$ Rao V. Mantri, ${ }^{1}$ and Rajesh Gandhi ${ }^{1}$
}

Received 15 April 2015; accepted 21 August 2015; published online 4 September 2015

\begin{abstract}
This study aimed in understanding the degradation behaviors of an $\operatorname{IgG} 1$ subtype therapeutic monoclonal antibody A (mAb-A) associated with $\mathrm{pH}$ and buffer species. The information obtained in this study can augment conventional, stability-based screening paradigms by providing the direction necessary for efficient experimental design. Differential scanning calorimetry (DSC) was used for studying conformational stability. Dynamic light scattering (DLS) was utilized to generate $B_{22}{ }^{*}$, a modified second virial coefficient for the character of protein-protein interaction. Size-exclusion chromatography (SEC) and hydrophobic interaction chromatography (HIC) were employed to separate degradation products. Sodium dodecyl sulfate-polyacrylamide gel electrophoresis (SDS-PAGE) was used for determining the molecular size and liquid chromatography mass spectrometry (LC-MS) were used for identifying the sequence of the separated fragments. The results showed that both $\mathrm{pH}$ and buffer species played the roles in controlling the degradation behaviors of $\mathrm{mAb}-\mathrm{A}$, but the $\mathrm{pH}$ was more significant. In particular, $\mathrm{pH} 4.5$ induced additional thermal transition peaks occurring at a low temperature compared with $\mathrm{pH} 6.5$. A continual temperature-stress study illustrated that the additional thermal transition peaks related to the least stable structure and a greater fragmentation. Although mAb-A showed the comparable conformational structures and an identical amount of aggregates at time zero between the different types of buffer species at $\mathrm{pH} 6.5$, the aggregation formation rate showed a buffer species-dependent discrepancy over a temperature-stress period. It was found that the levels of aggregations associated with the magnitudes of protein-protein interaction forces.
\end{abstract}

KEY WORDS: aggregation; conformational stability; fragmentation; monoclonal antibody (mAb); protein stability; thermal stability.

\section{INTRODUCTION}

Monoclonal antibodies (mAbs) are complex due to their large size and numbers of functional groups (1). Consequently, for any given $\mathrm{mAb}$ drug product, it is challenging to identify all of the potential modifications associated with real storage conditions during its drug product development period. Therefore, formulation development primarily focuses on identifying key modifications such as aggregation, fragmentation, oxidation, and deamidation since all those types of degradation reduce biological efficacy (2). Among those types of degradation, aggregation has been a major focus since it also causes immunogenic effects during therapy (3). A study illustrates that the greater conformation changes at low $\mathrm{pH}$ facilitate the higher levels of aggregation formation for monoclonal antibodies (4). Conversely, other studies show

\footnotetext{
${ }^{1}$ Drug Product Science and Technology, Bristol-Myers Squibb, One Squibb Drive, New Brunswick, New Jersey 08903, USA.

${ }^{2}$ To whom correspondence should be addressed. (e-mail: Songyan.zheng@bms.com)
}

that low $\mathrm{pH}$ causes the fragmentation of recombinant and humanized monoclonal antibodies, respectively $(5,6)$. It has been addressed that the degradation behaviors associate with the high specificity of each individual case in terms of kinetics and mechanism (7). Therefore, generalizing protein degradation behaviors is not suitable for the drug product development in pharmaceutical practice.

Differential scanning calorimetry (DSC) has been used to evaluate the likelihood of degradation (8), but it has been limited to predict the direction of degradation. Moreover, often the values of the major thermal transition temperatures $T_{\mathrm{m}}$ of any given monoclonal antibody formulated in the buffers with narrow $\mathrm{pH}$ range and slightly different salt concentrations are not able to be discerned. Therefore, formulations need to be evaluated under accelerated conditions such as elevated temperature (9), exposure to high shear (10), and freeze-thawing (11) in order to select the most promising formulation candidates within drug product development timeline.

This work was aimed at investigating the degradation behaviors of an IgG 1 subtype therapeutic monoclonal antibody $\mathrm{A}(\mathrm{mAb}-\mathrm{A})$ associated with $\mathrm{pH}$ and buffer species. The 
thermal stability and protein-protein interaction of $\mathrm{mAb}-\mathrm{A}$ in various formulation matrices were evaluated by DSC and dynamic light scattering (DLS), respectively. Usually any given active drug substance does not show degradation if it is stored at refrigerated temperature such as 2 to $8^{\circ} \mathrm{C}$ within the duration for formulation development. Therefore, temperature-induced stress study is widely used to obtain adequate degradation which can be captured by characterization methods. The knowledge obtained from the temperatureinduced study is assumed to be relevant with degradation tendency in a real storage condition. In this study, the most promising formulation candidates selected on the basis of DSC results were stressed at a commonly applied temperature of $40^{\circ} \mathrm{C}$ to obtain adequate degradation which could be captured by characterization methods such as size-exclusion chromatography (SEC), hydrophobic interaction chromatography (HIC), sodium dodecyl sulfate-polyacrylamide gel electrophoresis (SDS-PAGE), and liquid chromatography mass spectrometry (LC-MS).

\section{MATERIALS AND METHODS}

\section{Materials}

The mAb-A is an IgG 1 subtype monoclonal antibody which was produced using conventional biopharmaceutical Chinese hamster ovary ( $\mathrm{CHO}$ ) cells production (Bristol Myers Squibb, Princeton, NJ). Sodium chloride, sodium citrate, sodium phosphate monobasic, sodium acetate, and sodium phosphate dibasic were all purchased (Mallinckrodt, St. Louis, MO). Sterile water for injection (B|BRAUN, Bethlehem, PA) was used in the preparation of all buffers.

\section{Protein Concentration Determination}

Initial protein solutions of $8-10 \mathrm{mg} / \mathrm{mL}$ were prepared in three different buffer species solutions and then filtered using sterile 33-mm, 0.22- $\mu \mathrm{m}$ syringe disk filters (Merck Millipore Ltd, Bedford). Seven different dilutions were prepared between the initial concentrations and $0.8-0.9 \mathrm{mg} / \mathrm{mL}$. Each of the diluted protein solutions was centrifuged using an Eppendorf centrifuge (Brinkmann Instruments, Germany) at $13,000 \mathrm{rpm}$ for $6 \mathrm{~min}$. The protein concentrations of all the samples were determined using a NanoDrop Spectrophotometer (Thermo Scientific, Delaware) by the direct UV A280 method. The principle of this method is that protein molecules in the solution adsorb ultraviolet light with absorbance maxima at $280 \mathrm{~nm}$. The relationship of absorbance to protein concentration is linear based on Beer-Lamber equation, $A=\varepsilon$ $l c ; A$ is the absorbance value, $\varepsilon$ is the wavelength-dependent extinction coefficient, $l$ is the path length in centimeter, and $c$ is the analyte concentration. In this study, the experimental extinction coefficient of the mAb-A was used to calculate concentration.

\section{Differential Scanning Calorimetry}

Protein samples were prepared at $0.4 \mathrm{mg} / \mathrm{mL}$ in various buffers and then scanned at a rate from 25 to $95^{\circ} \mathrm{C} / \mathrm{h}$ using a VP-Capillary DSC Platform (MicroCal, LLC, Northampton, MA). Protein concentrations were determined with high accuracy using a Varian Cary 100 Bio Spectrophotometer (Agilent Technologies, Santa, Clara, CA). The major transition temperature $\left(T_{\mathrm{m}}\right)$ and the onset temperature $\left(T_{\mathrm{m} \text {-onset }}\right)$ of the major transition for each sample were then determined using MicroCal VP-Capillary DSC Automated Analysis, Origin 7.

\section{Light Scattering}

The light scattering intensities were measured using Malvern Nano ZS with $173^{\circ}$ backscatter using a 632.8-nm laser (Malvern, UK) with an instrumental attenuation. The experimental scattering intensities were fitted according to the model presented in Eq. 1, where $R$ is designated as Rayleigh ratio, $K$ represents an instrument constant, $M_{\mathrm{w}}$ is designated as an average molecular weight, $C$ is designated as protein concentration, and $B_{22}$ is designated as the second virial coefficient.

$\frac{R}{K}=\frac{M_{\mathrm{w}} c}{1+M_{\mathrm{w}} B_{22} c}$

The instrument constant $K$ is defined by $K=\frac{4 \pi^{2} n_{0}^{2}(\mathrm{dn} / \mathrm{dc})^{2}}{N_{\mathrm{A}} \lambda_{0}^{4}}$, where $n_{0}$ is the refractive index of the buffer, $\mathrm{dn} / \mathrm{dc}$ is the protein differential refractive index increment, $N_{\mathrm{A}}$ is Avogadro's number, and $\lambda_{0}$ is the laser wavelength in vacuum. The value of $\mathrm{dn} / \mathrm{dc}$ used for the calculation of $K$ was $0.185 \mathrm{~mL} / \mathrm{g}$.

\section{Size-Exclusion Chromatography}

The selected formulations stressed at $40^{\circ} \mathrm{C}$ were analyzed by size-exclusion chromatography (SEC) using a Waters Alliance 2690/2695 Separations Module (Waters Corporation, Milford, MA) equipped with a TSK Gel G3000SW ${ }_{\mathrm{XL}}$ SizeExclusion Column $(7.8 \mathrm{~mm} \times 30 \mathrm{~cm}, 5 \mu \mathrm{m}$ Tosoh Bioscience), a

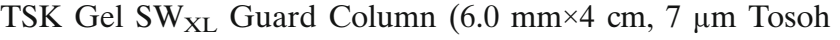
Bioscience), and a Waters 2996 Photodiode Array Detector (PDA). The mobile phase was a solution containing $10 \mathrm{mM}$ phosphate, $27 \mathrm{mM}$ potassium chloride, $137 \mathrm{mM}$ sodium chloride, and $1.76 \mathrm{mM}$ potassium phosphate with a flow rate of $0.85 \mathrm{~mL} / \mathrm{min}$. Chromatograms were monitored at $215 \mathrm{~nm}$, and the data was processed using Empower 2 Software (Waters). The fractions eluted from the column were collected at retention times of 9.5 to $10.9 \mathrm{~min}$ for the native monomer, 10.9 to $11.6 \mathrm{~min}$ for the shoulder of the monomer, and 12.3 to $13.5 \mathrm{~min}$ for fragments. Each collected fraction was injected back into SEC column to confirm the content. The confirmed fractions were then further analyzed using liquid chromatography mass spectrometry (LC-MS) and hydrophobic interaction chromatography (HIC).

\section{Hydrophobic Interaction Chromatography}

Neat formulations as well as the corresponding fractions collected from the SEC column were analyzed by HIC using a Waters Alliance 2690/2695 Separations Module (Waters Corporation, Milford, MA) equipped with a TosoHaass Ether 5PW HIC Column $(7.5 \mathrm{~cm} \times 7.5 \mathrm{~mm}$ ID, Cat.\# 08641) and a Waters 2996 photodiode array detector (Waters Corporation, 
Milford, MA). Mobile phase A was $2 \mathrm{M}$ ammonium sulfate $\left(\left(\mathrm{NH}_{4}\right)_{2} \mathrm{SO}_{4}\right)$ with $0.1 \mathrm{M}$ sodium phosphate $\left(\mathrm{Na}_{3} \mathrm{PO}_{4}\right)$ at $\mathrm{pH} 7$, and mobile phase $\mathrm{B}$ was $0.1 \mathrm{M}$ sodium phosphate $\left(\mathrm{Na}_{3} \mathrm{PO}_{4}\right)$ at $\mathrm{pH}$ 7. Depending on the concentration of the sample, the injection volume ranged between 50 and $100 \mu \mathrm{L}$. Chromatograms were monitored at $215 \mathrm{~nm}$, and data was collected and analyzed using Empower 2 Software (Waters).

\section{Liquid Chromatography Mass Spectrometry}

An Agilent HPLC coupled to an AB Sciex Q-Star (QTOF) mass spectrometer was used for the determination of intact antibody and fragments. In addition, a Waters Acquity (UPLC) coupled to a Thermo Fisher LTQ was employed for all tryptic peptide sequence confirmation. Experimental conditions were described elsewhere $(12,13)$.

\section{SDS-Polyacrylamide Gel Electrophoresis}

SDS-PAGE was performed using Tris-HCl 4-15\% gel (Bio-Rad Cat: \# 345-0027) under non-reducing conditions. The samples were prepared in Laemmli sample buffer and heated at $100^{\circ} \mathrm{C}$ for $2 \mathrm{~min}$. Each well was then loaded with $0.5 \mu \mathrm{g}$ of protein sample. The gel was run on $120 \mathrm{~V}$ for $\sim 120 \mathrm{~min}$ in a Bio-Rad electrophoresis buffer and POWER/ PAC 1000 (Bio-Rad, Hercules, CA).

\section{RESULTS}

\section{Differential Scanning Calorimetry}

As shown in Table I, $T_{\mathrm{m} \text {-onset }}$ and $T_{\mathrm{m}}$ followed the same general trends; the formulation containing $20 \mathrm{mM} \mathrm{NaCl}$ at $\mathrm{pH}$ 6.5 possessed the highest $T_{\mathrm{m}}$ value regardless of buffer species. Moreover, $T_{\mathrm{m}}$ values at $\mathrm{pH} 6.5$ were comparable between buffer species. As indicated in Table I as well, the formulations in acetate buffer at $\mathrm{pH} 4.5$ exhibited the lowest $T_{\mathrm{m}}$ values. The slight discrepancy between the values was due to the difference of the concentrations of $\mathrm{NaCl}(20 \mathrm{vs} .100 \mathrm{mM})$.
The DSC profiles derived from the formulations with the highest $T_{\mathrm{m}}$ values selected from each buffer group as well as the formulation representing the group of the lowest $T_{\mathrm{m}}$ value are compared in Fig. 1. Not only $T_{\mathrm{m}}$ values are comparable but also the major thermal transition traces for the formulations including phosphate $\mathrm{pH} 6.5$, citrate $\mathrm{pH} 6.5$, and acetate $\mathrm{pH} 6.5$ are similar. In comparison, the DSC trace of mAb-A of acetate $\mathrm{pH} 4.5$ shows an additional transition occurring at lower temperature. Acetate $\mathrm{pH} 4.5$ containing $20 \mathrm{mM} \mathrm{NaCl}$ was selected to compare with other DSC profiles since it contained the same concentration of $\mathrm{NaCl}$ with other buffers at $\mathrm{pH} 6.5$.

\section{Light Scattering (LS)}

Table II shows the modified second virial coefficient $\left(B_{22} *\right)$ values, obtained by dividing the experimental virial coefficient $B_{22}$ by $B_{22}{ }^{\text {hs }}\left(B_{22}{ }^{*}=B_{22} / B_{22}{ }^{\text {hs }}\right)$, where $B_{22}{ }^{\text {hs }}$ was calculated as four times the molecular volume of mAb-A. The $B_{22} *$ values for formulations of phosphate $\mathrm{pH} 6.5$, citrate $\mathrm{pH} 6.5$, and acetate $\mathrm{pH} 6.5$ are all negative, indicating the attractive interaction. In addition, the magnitudes of $B_{22} *$ follow the order of phosphate $\mathrm{pH} 6.5>$ citrate $\mathrm{pH} 6.5>$ acetate $\mathrm{pH}$ 6.5.

\section{Size-Exclusion Chromatography}

While the SEC chromatograms for each of the four selected formulations were identical at the initial time point (data not shown), the relative level of aggregates and fragments varied after being stressed at $40^{\circ} \mathrm{C}$ for 6 weeks. Figure 2 shows the kinetics of degradation of $\mathrm{mAb}-\mathrm{A}$ in the four selected formulations. In Fig. 2a, the percentage of aggregation is plotted as a function of incubation time to reveal the relative rank order for aggregation: phosphate $\mathrm{pH} 6.5>$ citrate $\mathrm{pH}$ $6.5 \geq$ acetate $\mathrm{pH} 6.5>$ acetate $\mathrm{pH}$ 4.5. As revealed in Fig. 2b, fragmentation of mAb-A in acetate $\mathrm{pH} 4.5$ is significantly higher than others. Considering all degradation processes evaluated, the overall degradation of mAb-A is highest in

Table I. Formulation Compositions: the Thermal Transition Temperature Onset ( $T_{\mathrm{m} \text {-onset }}$ ) with Standard Deviations $\mathrm{SD}_{\mathrm{m} \text {-onset }}$ and the $T_{\mathrm{m}}$ with Deviations $\mathrm{SD}_{\mathrm{m}}$ Obtained from the DSC Auto-analysis

\begin{tabular}{|c|c|c|c|c|c|c|}
\hline $\begin{array}{l}\text { Buffering agents } \\
(20 \mathrm{mM})\end{array}$ & $\begin{array}{l}\mathrm{NaCl} \\
(\mathrm{mM})\end{array}$ & $\mathrm{pH}$ & $\begin{array}{l}T_{\text {m-onset }} \\
\left({ }^{\circ} \mathrm{C}\right)\end{array}$ & $\begin{array}{l}\mathrm{SD}_{\mathrm{m} \text {-onset }} \\
\left({ }^{\circ} \mathrm{C}\right)\end{array}$ & $T_{\mathrm{m}}$ & $\mathrm{SD}_{\mathrm{m}}$ \\
\hline \multirow[t]{4}{*}{ Sodium phosphate } & \multirow[t]{2}{*}{20} & 6.5 & 61.99 & 0.14 & 72.31 & 0.14 \\
\hline & & 7.5 & 61.64 & 0.14 & 71.96 & 0.32 \\
\hline & \multirow[t]{2}{*}{100} & 6.5 & 61.71 & 0.12 & 72.04 & 0.13 \\
\hline & & 7.5 & 61.46 & 0.18 & 71.78 & 0.29 \\
\hline \multirow[t]{6}{*}{ Sodium citrate } & \multirow[t]{3}{*}{20} & 5.5 & 60.71 & 0.26 & 71.44 & 0.05 \\
\hline & & 6.5 & 61.23 & 0.01 & 72.29 & 0.24 \\
\hline & & 7.5 & 61.01 & 0.14 & 71.34 & 0.09 \\
\hline & \multirow[t]{3}{*}{100} & 5.5 & 59.67 & 0.18 & 71.21 & 0.15 \\
\hline & & 6.5 & 61.41 & 0.26 & 71.74 & 0.09 \\
\hline & & 7.5 & 61.15 & 0.14 & 71.48 & 0.15 \\
\hline \multirow[t]{6}{*}{ Sodium acetate } & \multirow[t]{3}{*}{20} & 4.5 & 60.79 & 0.01 & 71.12 & 0.09 \\
\hline & & 5.5 & 60.30 & 0.24 & 71.81 & 0.14 \\
\hline & & 6.5 & 61.40 & 0.08 & 72.51 & 0.04 \\
\hline & \multirow[t]{3}{*}{100} & 4.5 & 59.26 & 0.14 & 69.99 & 0.12 \\
\hline & & 5.5 & 60.20 & 0.07 & 71.33 & 0.17 \\
\hline & & 6.5 & 61.04 & 0.19 & 72.01 & 0.14 \\
\hline
\end{tabular}




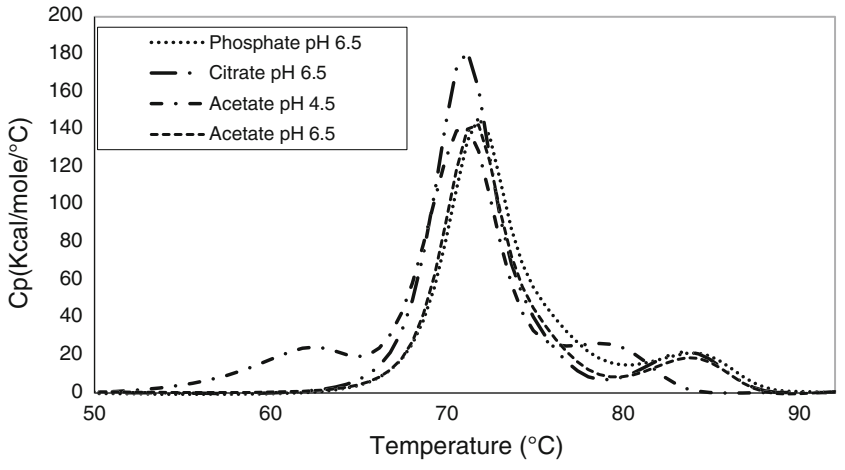

Fig. 1. DSC thermal transition profiles of mAb-A in phosphate $\mathrm{pH}$ 6.5 , citrate $\mathrm{pH} 6.5$, acetate $\mathrm{pH} 4.5$, and acetate $\mathrm{pH} 6.5$ in the presence of $20 \mathrm{mM} \mathrm{NaCl}$

acetate $\mathrm{pH} 4.5$, followed by phosphate $\mathrm{pH} 6.5$, acetate $\mathrm{pH} 6.5$, and citrate $\mathrm{pH} 6.5$ as shown in Fig. 2c.

\section{Hydrophobic Interaction Chromatography}

For further analysis, the fraction of the fragment peak of acetate $\mathrm{pH} 4.5$, isolated by the SEC column was analyzed by the HIC as well. The analysis confirmed that the fraction of the single SEC fragment peak contained two components corresponding to the two minor peaks of the HIC chromatogram, as shown in Fig. 3. The peak occurred at the left side of the main peak (monomer peak) shows larger area compared with that occurred at the right side. These results indicated that larger component was more hydrophilic while smaller component was more hydrophobic compared with monomer.

\section{Liquid Chromatography Mass Spectrometry}

The monomer peak and shoulder fractions isolated from the SEC column were further analyzed by LC-MS spectrometry, which revealed very similar amino acid sequences. The fragment fraction collected by SEC was analyzed by LC-MS as well. The analysis indicated that this fraction mainly consisted of a group of antibody fragments with amino acid sequences which included the entire light chain and a small portion of a partial heavy chain.

\section{SDS-PAGE}

The fractions of the shoulder and the fragment peak of $\mathrm{mAb}-\mathrm{A}$ in acetate $\mathrm{pH} 4.5$ isolated from the SEC column were

Table II. $B_{22} *$ Values for mAb-A in Phosphate $\mathrm{pH}$ 6.5, Citrate $\mathrm{pH}$ 6.5, and Acetate $\mathrm{pH}$ 6.5 Containing $20 \mathrm{mM} \mathrm{NaCl}$ with Deviations $\mathrm{SD}_{B 22^{*}}$

\begin{tabular}{lcc}
\hline Formulations & $B_{22}{ }^{*}$ & $\mathrm{SD}_{B 22^{*}}$ \\
\hline Phosphate pH 6.5 & -1.20 & 0.08 \\
Citrate pH 6.5 & -1.04 & 0.10 \\
Acetate pH 6.5 & -0.63 & 0.16 \\
\hline
\end{tabular}

$S D$ standard deviation
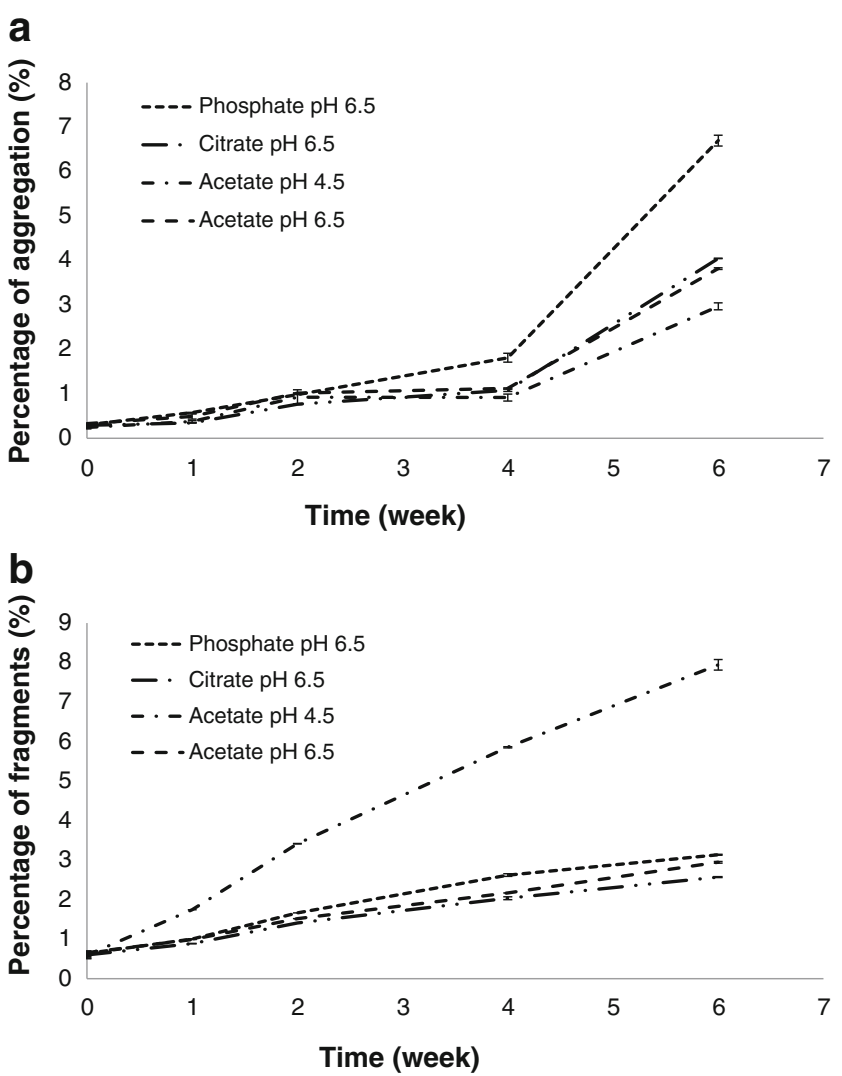

C

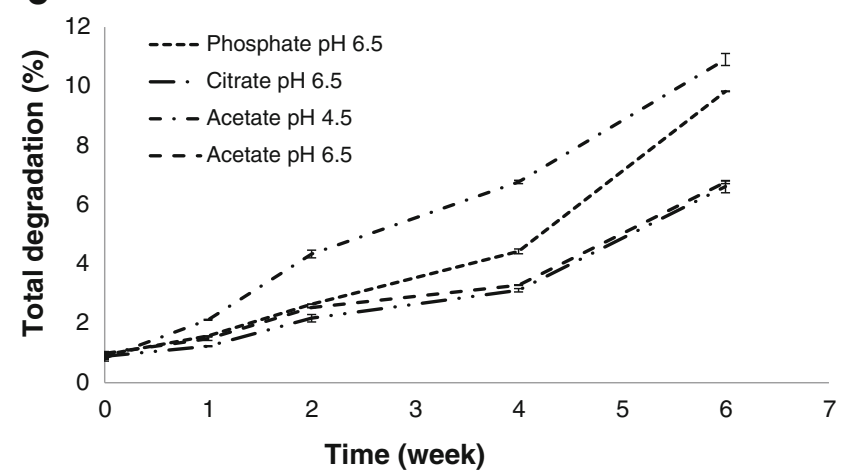

Fig. 2. Degradation of $m A b-A$ as a function of incubation time in the four selected formulations: Panel a shows aggregation as a function of incubation time; panel b shows fragmentation as a function of incubation time, and panel $\mathbf{c}$ represents total degradation (i.e., aggregation+ fragmentation) as a function of incubation time

also analyzed by SDS-PAGE. The shoulder fraction consisted of a band occurring at $110 \mathrm{kDa}$ with a small fraction at $175 \mathrm{kDa}$ band. The fragment peak fraction contains two components which manifests as bands at 44.6 and $22.6 \mathrm{kDa}$ as shown in Fig. 4.

\section{DISCUSSION}

\section{Aggregation Behaviors Influenced by Buffer Species}

In this study, formulations were designed by selecting the buffer species that covered an empirical $\mathrm{pH}$ range and their 


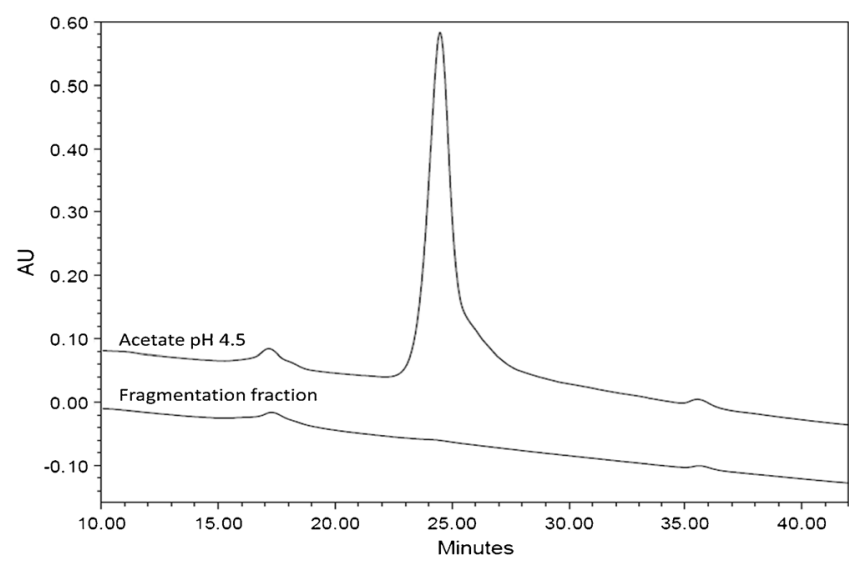

Fig. 3. Comparison of the HIC chromatogram of mAb-A in acetate $\mathrm{pH} 4.5$ with that of the fragment fraction isolated from the SEC column

corresponding $\mathrm{pH}$ capacities which were not in the vicinity of the isoelectric point ( $\mathrm{pI}$ ) of $\mathrm{mAb}-\mathrm{A}$. As shown in the "RESULTS" section (Table I), the $T_{\mathrm{m}}$ values derived from the most promising buffer compositions including phosphate, citrate, and acetate formulations at $\mathrm{pH} 6.5$ are equivalent. The thermal transition profiles also are similar as shown in Fig. 1. Altogether, the results suggesting the conformational structures of those three different types of buffer species at $\mathrm{pH} 6.5$ are comparable. After the initial DSC screening, the most promising formulations at $\mathrm{pH} 6.5$ were selected to further study the degradation behaviors impacted by the buffer species. As shown in Fig. 2a, the primary degradation for the three formulations at $\mathrm{pH} 6.5$ is aggregation and the quantity followed an order: phosphate $\mathrm{pH} 6.5>$ citrate $\mathrm{pH} 6.5 \geq$ acetate

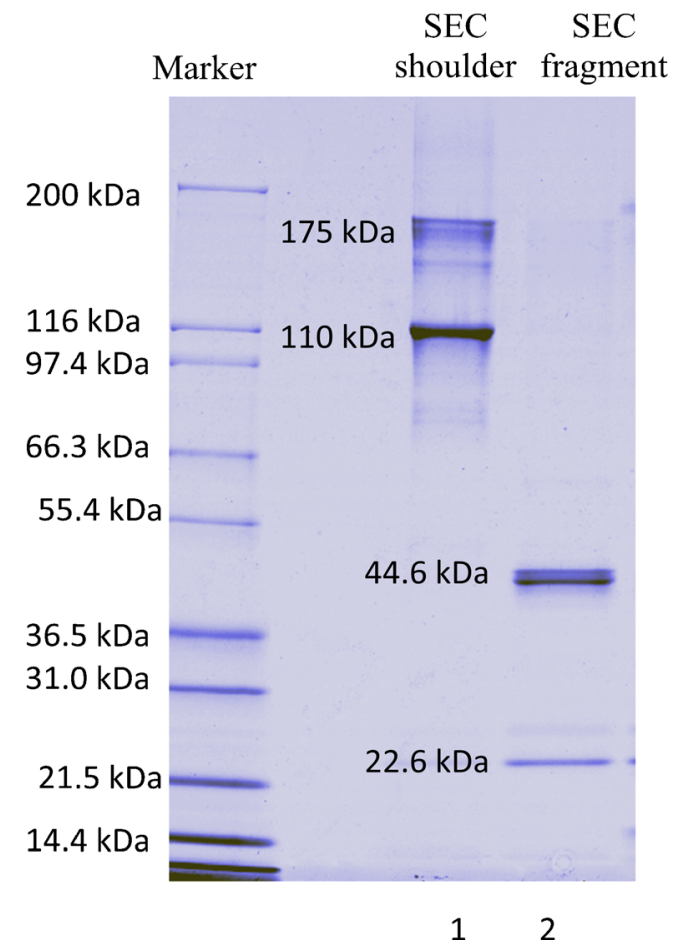

Fig. 4. SDS-PAGE gel image of the shoulder and fragment fractions isolated by SEC
$\mathrm{pH}$ 6.5. Since the initial conformational structures are discernible, it is not able to correlate the aggregation formation with the conformational structure. On the other hand, the attractive interaction is different evidenced by $B_{22} *$ values as displayed in Table II. Furthermore, the order of the aggregation formation is consistent with the strength of attractive forces. Taken together suggesting that the aggregation formation is primarily controlled by the attractive interaction. Since three formulations contained the same concentration of $\mathrm{NaCl}$ and the $\mathrm{pH}$ values are identical, the apparent differences on the aggregation levels are likely due to the buffer species that induced different attractive forces among three buffer species.

\section{Fragmentation Induced by $\mathrm{pH} 4.5$}

Acetate $\mathrm{pH} 4.5$ and acetate $\mathrm{pH} 6.5$ had the same concentration of $\mathrm{NaCl}$, yet different $\mathrm{pH}$ values; the effect of solution $\mathrm{pH}$ on formulation stability, therefore, was studied. The primary degradation of acetate $\mathrm{pH} 4.5$ was fragmentation as shown in Fig. 2b. To study the fragmentation behaviors of $\mathrm{mAb}-\mathrm{A}$ in this formulation, the shoulder and fragment fraction were collected by SEC separation followed by structure elucidation using SDS-PAGE and LC-MS. The results obtained from LC-MS study confirmed that the shoulder isolated from SEC column had a similar amino acid sequence as the monomer itself. Furthermore, SDS-PAGE image shows that the shoulder possessed a molecular weight of $110 \mathrm{kDa}$. All together suggesting that the component of the shoulder consisted of a molecular weight of $110 \mathrm{kDa}$ with the similar amino sequence of the monomer, and it was more hydrophobic compared with the monomer.

The results obtained from HIC (Fig. 3) revealed that the fragment peak fraction isolated from the SEC column contained two components: hydrophilic and hydrophobic components, in comparison with the monomer. Further study with LC-MS (data are not shown) showed that the larger component mainly consisted of a group of fragments with a mass at $42 \mathrm{kDa}$ and an amino acid sequence of the entire light chain. This mass was exactly double of the theoretical mass of the intact light chain. This led to a hypothesis that the larger component was likely due to the assembly of the two light chains. As reported in the literature, the hydrophobic sites of proteins are often buried in the oligomerization states because of the self-assembly driven by hydrophobic-hydrophobic interaction $(14,15)$. In this case, the more hydrophilic nature of the double chain could be the result of the self-assembly of the two light chains, driven by the hydrophobic-hydrophobic interaction as well, where the hydrophobic sites of the light chains were buried in the core of the interaction. As a result, the surface of the double light chain was more hydrophilic than that of the native monomer. For the smaller component, it consisted of a potion of amino acid sequence of the $\mathrm{CH} 2$ domain, and this fraction was much more hydrophobic compared with the monomer (Fig. 3). This was presumably due to the exposure of the hydrophobic sites to the surface due to the denaturation of $\mathrm{CH} 2$ domain. The degradation mechanism on the fragmentation is displayed in Fig. 5.

The overall degradation of mAb-A in acetate $\mathrm{pH} 4.5$ was the highest among the formulations as shown in Fig. $2 \mathrm{c}$ and the greater part was fragment forms due to the hydrolysis. It has been suggested that the thermal transition peak occurring at a 


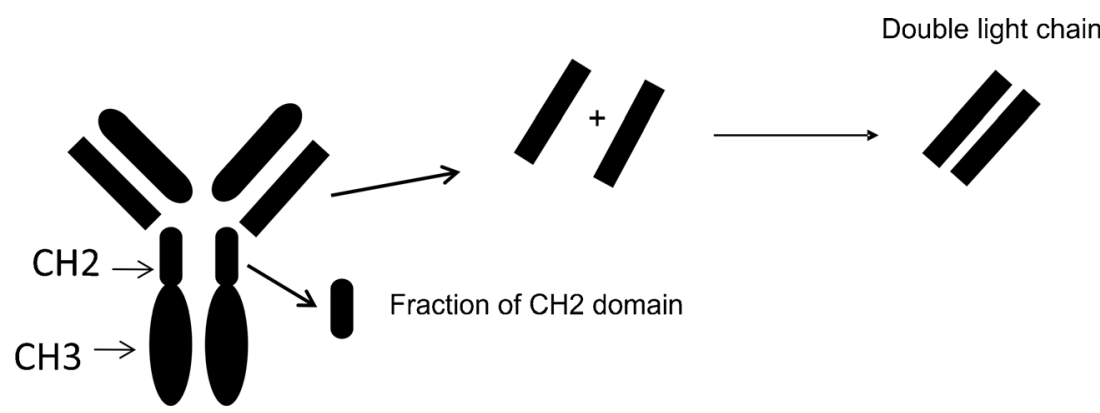

Fig. 5. A proposed mechanism for mAb-A fragmentation induced by acidic $\mathrm{pH} 4.5$

low temperature is due to the unfolding of $\mathrm{CH} 2$ domain (11). Taken together leading to a hypothesis that the $\mathrm{CH} 2$ domain was unfolded by acetate $\mathrm{pH}$ 4.5. Consequently, the loose state of $\mathrm{CH} 2$ domain triggered unfolding of whole mAb-A molecule. As a result, the surface accessibility of mAb-A to acidic $\mathrm{pH} 4.5$ solution was increased, which might cause more fragmentation.

It has been reported that a humanized $\mathrm{mAb}$ is the most stable in citrate buffer at $\mathrm{pH}$ 5.0-5.5 (16). Another study indicates that two mAbs are less stable in citrate buffer, and aggregation is minimal in Tris- $\mathrm{HCl}$ buffer at $\mathrm{pH} 7.2$ and 8 (17). This investigation showed that mAb-A was the most stable in citrate buffer at $\mathrm{pH}$ 6.5. Structurally, mAbs are proteins consisting of two light chains and two heavy chains with Y-shaped motif. Although all proteins motioned above are monoclonal antibodies with the same motif, the specificity of each of those mAbs depends on its own amino acid sequence. The different optimal $\mathrm{pHs}$ reflect the uniqueness of the amino acid sequence in controlling stability.

It has been known that buffer species differentially alter the conformational stability of a mAb and cause fragmentation (18). In contrast, the conformational structure of mAb-A in different buffer species phosphate, citrate, and acetate at pH 6.5 was similar and the aggregation was primarily influenced by the attractive protein-protein interaction. The comparison between previous studies and the investigation conducted here indicated the high specificity of each individual monoclonal antibody in terms of degradation behaviors. The results obtained from this study were used to direct the formulation design for the late-stage drug product development of mAb-A. Through 9-month stability data collected from the samples stored at $2-8^{\circ} \mathrm{C}$, the formulation of $\mathrm{mAb}$ A mainly consisting of $20 \mathrm{mM}$ citrate and $50 \mathrm{mM} \mathrm{NaCl}$ at $\mathrm{pH}$ 6.5 was superior to other formulation candidates.

\section{CONCLUSIONS}

The degradation behaviors of $\mathrm{mAb}-\mathrm{A}$ were investigated through a comprehensive assessment including the analysis of conformational stability, the protein-protein interaction, and the extensive characterization of degradation pathways. It was found that $\mathrm{pH} 4.5$ caused more fragmentation compared with the same buffer species at $\mathrm{pH}$ 6.5. The observed fragments included the derivative of monomer with a molecular weight of $110 \mathrm{kDa}$, light chain, and the portion of $\mathrm{CH} 2$ domain. In addition, $\mathrm{pH} 4.5$ induced the unfolding of $\mathrm{CH} 2$ domain that increased the surface accessibility of mAb-A. Consequently, the enhanced surface accessibility might facilitate the fragmentation. Although the conformational structure of mAb-A in the buffer species of phosphate $\mathrm{pH} 6.5$, citrate $\mathrm{pH} 6.5$, and acetate $\mathrm{pH} 6.5$ were similar, the potency of the protein-protein interaction was different. It was found that the strength of the attractive protein-protein interaction correlated with aggregation formation. Taken together, the results derived from this study suggested that the attractive protein-protein interaction played the major role in controlling aggregation formation of $\mathrm{mAb}-\mathrm{A}$. The comparison between this study and literature reports further demonstrated the high specificity of each individual monoclonal antibody in terms of degradation behaviors with respect to buffer conditions. In general, the knowledge obtained from this study should be useful as a reference for formulation development but it could not be extrapolated to other mAbs.

\section{ACKNOWLEDGMENTS}

The authors thank Dr. Munir Hussain for reviewing this manuscript, Dr. Ajit Narang for providing comments on the manuscript, and Dr. Erinc Sahin for fitting the static light scattering data.

\section{REFERENCES}

1. Wang W, Singh S, Zheng D, King K, Nema S. Antibody structure, instability, and formulation. J Pharm Sci. 2007;96:1-25.

2. Daugherty AL, Mrsny R. Formulation and delivery issues for monoclonal antibody therapeutics. Adv Drug Deliv Rev. 2006;58:686-706.

3. Rosenberg AS. Effects of protein aggregates: an immunologic perspective. AAPS J. 2006;8:E501-7.

4. Ejima D, Tsumoto K, Fukada H, Yumioka R, Nagase K, Arakawa T, et al. Effects of acid exposure on the conformation, stability, and aggregation of monoclonal antibodies. Proteins. 2007;66:954-62.

5. Gaza-Bulseco G, Liu H. Fragmentation of a recombinant monoclonal antibody at various $\mathrm{pH}$. Pharm Res. 2008;25:188190.

6. Salinas B, Sathish H, Shah A, Carpenter J, Randolph T. Bufferdependent fragmentation of a humanized full-length monoclonal antibody. J Pharm Sci. 2010;99:2962-74.

7. Morris AM, Watzky MA, Finke RG. Protein aggregation kinetics, mechanism and curve-fitting: a review of the literature. Biochim Biophys Acta. 2009;1794:375-97.

8. Wen J, Jiang Y, Nahri L. Effect of carbohydrate on thermal stability of antibodies. Am Pharm Rev. 2008;11:102-4.

9. Liu H, Gaza-Bulseco G, Joanne SJ. Characterization of the stability of a fully human monoclonal $\mathrm{IgG}$ after prolonged incubation at elevated temperature. J Chromatogr B. 2006;837:35-43. 
10. Bee JS, Stevenson JL, Mehta B, Svitel J, Pollastrini J, Platz R, et al. Response of a concentrated monoclonal antibody formulation to high shear. Biotechnol Bioeng. 2009;103(5):936-43.

11. Hawe A, Kasper JC, Friess W, Jiskoot W. Structure properties of monoclonal antibody aggregates induced by freeze-thawing and thermal stress. Eur J Pharm Sci. 2009;38:79-87.

12. Dick Jr LW, Mahon D, Qiu D, Cheng KC. J Chromatogr B. 2009;877:230-6.

13. Dick Jr LW, Qiu D, Wong RB, Cheng KC. Biotechnol Bioeng. 2009;105:515-23.

14. Zheng S, Strzalka J, Jones DH, Opella SJ, Blasie JK. Comparative structural studies of $\mathrm{Vpu}$ peptides in phospholipid monolayers by X-ray scattering. Biophys J. 2003;84:42393-415.
15. Ye S, Strzalka J, Churbanova IY, Zheng S, Johansson JS, Blasie JK. A model membrane protein for binding volatile anesthetics. Biophys J. 2004;87:4065-74.

16. Zheng J, Janis L. Influence of $\mathrm{pH}$, buffer species, and storage temperature on physicochemical stability of a humanized monoclonal antibody LA298. Int J Pharm. 2006;308:46-51.

17. Joshi V, Shivach T, Kumar V, Yadav N, Rathore A. Avoiding antibody aggregation during processing: establishing hold times. Biotechnol J. 2014;9:1195-205.

18. Ionescu RM, Vlasak J, Price C, Kirchmeier M. Contribution of variable domains to the stability of humanized IgG1 monoclonal antibodies. J Pharm Sci. 2008;98:1414-26. 